\title{
EL PÁRRAFO COMO UNIDAD DISCURSIVA
}

\author{
AgUSTÍN VERA LUJÁN \\ Universidad Nacional de Educación a Distancia (UNED) \\ agustinvera@flog.uned.es
}

\begin{abstract}
Resumen
Tras pasar revista a algunas de las propuestas de caracterización del párrafo, se opta por una definición de esta unidad como elemento del ámbito de lo textual que posee características definitorias desde una perspectiva sintáctica, semántica y pragmática. Se ponen también de manifiesto los mecanismos lingüístico-cognitivos a que obedecen las relaciones de dominio entre el párrafo y sus constituyentes y los resultados que de ellas de derivan para la configuración final del párrafo como unidad.
\end{abstract}

PALABRAS CLAVE: párrafo, texto, discurso, unidades discursivas, unidades textuales.

\begin{abstract}
After reviewing several proposals to characterize the paragraph, we choose a definition of this unit in line with its status as a unit of the discourse level, highlighting its defining aspects from a syntactic, semantic and pragmatic point of view. We also consider the linguistic and cognitive mechanisms that govern the relations of domination between the paragraph and its constituents, and the results derived from this relations for the final configuration of the paragraph as a unit.
\end{abstract}

KEY WORDS: paragraph, text, discourse, discourse units, text units.

La investigación sobre sus niveles y unidades de análisis no es una cuestión que haya ocupado un espacio central, de manera generalizada, dentro del marco de la lingüística del texto o del discurso. Esta situación afecta de manera especial a las investigaciones que tienen como objeto los textos o discursos escritos, pues, mientras los estudios sobre el discurso oral han prestado una atención notable a la delimitación y definición de sus unidades de análisis, llegando a establecer un inventario muy perfilado de las mismas, así como de las relaciones jerárquicas que estas establecen entre sí, aquellos que se han centrado más preferentemente en los textos o discursos escritos no han alcanzado a este respecto un grado de desarrollo equivalente.

Entre las unidades de análisis del discurso escrito le corresponde, sin duda, al párrafo la condición de unidad que ha recibido una mayor atención, cuando no la de unidad lingüístico-textual por excelencia, al margen, claro está, del texto o discurso mismos. No obstante, esta condición del párrafo como unidad incuestionablemente central en la 
operatividad de los productos textuales o discursivos no implica que se haya configurado hasta la fecha una caracterización del mismo que pueda considerarse razonablemente cerrada, por satisfactoria, y medianamente generalizada. Abundan, al contrario, todavía aproximaciones intuitivas y difusas a la mencionada unidad y, en muchas ocasiones, su estudio se aborda sin tomar en consideración los aspectos esenciales a los que es necesario atender para lograr una explicación adecuada de sus propiedades fundamentales.

El objeto de nuestro trabajo es definir el párrafo como unidad característica de un nivel textual/discursivo específico, y describir sus propiedades fundamentales en tanto que unidad semiótica, para lo cual es necesario tomar en consideración su funcionamiento en los componentes semántico, sintáctico y pragmático.

La tarea de esbozar una definición explicativamente adecuada de la unidad párrafo debe partir, sin duda, de la asunción de que este nivel lingüístico textual/discursivo es una dimensión de naturaleza esencialmente semántico-conceptual. Siendo el texto una unidad de sentido, como unidad textual el párrafo participa de esta misma naturaleza, tratándose, también en su caso, de una unidad semántico-conceptual de partida.

Esta condición semántico-conceptual del párrafo ha sido muy ampliamente advertida por la práctica generalidad de las aproximaciones lingüísticas que han procurado su caracterización como unidad. Así, se ha destacado, en ocasiones, que se trata de una unidad cuyos distintos componentes desarrollarían o estarían relacionados con un mismo tema (Cassany, 1995), remitirían a una sola idea (Serafini, 1989; Garachana y Montolío, 2000), o a un mismo concepto (Longacre, 1979). La RAE (1981) consideraba el asunto tratado, y su unidad, lo que los distintos componentes o constituyentes del párrafo tendrían en común, de manera que el cambio de asunto o un tratamiento del mismo en un aspecto diferente llevarían consigo un cambio de párrafo (RAE, 1981: 148-149). En sentido parecido, Brooks y Warren (1949: 355-356) consideran lo característico del párrafo el ser la unidad donde se desarrolla para el lector un determinado tópico.

En ocasiones, se ha intentado concretar o formalizar estas diferentes indicaciones sobre la unidad temática o conceptual del párrafo señalando que a cada una de estas unidades le correspondería una oración tópica en relación con la cual el resto del párrafo funcionaría como un desarrollo o comentario, que vendría a ampliar las informaciones ancladas sobre el tópico mencionado (Harris, 1952; González Cobas, 2002).

Caracterizaciones semejantes suscitan, al menos, dos tipos de problemas diferentes que desaconsejan, en nuestra opinión, su adopción como definiciones válidas, descriptiva y explicativamente, del párrafo. 
Desde el punto de vista de su adecuación descriptiva, en efecto, si nociones tan vagas como las de "tema" o "idea" se concretan en una fórmula como la de las oraciones tópicas desarrolladas merced a un comentario posterior, no es un problema menor la existencia de párrafos que no se acomodan en absoluto a esta estructura 'tópicocomentario'. Como han señalado, por ejemplo, Larsen (1976) para el inglés, o Sánchez Escobar (1996) para el caso del español, es posible, en efecto, encontrar párrafos en ambas lenguas en los que no es posible identificar ninguna oración tópica. Ello es, como señala Sánchez Escobar, especialmente frecuente, por comparación con el inglés, en español, donde encontramos, en efecto, párrafos del tipo de los que constituyen un texto como el de $(1)^{1}$, en los que no es posible identificar ninguna oración tópica, en el sentido a que nos venimos refiriendo:

(1) Elaboración de la receta de Sargo a la libanesa:

Corta la parte blanca del puerro en juliana, los ajos tiernos en dos a lo largo, el chile en bastones y ralla la zanahoria. Saltea todas las verduras en una sartén con un chorro de aceite. Espolvorea con un poco de perejil picado.

Prepara un aliño mezclando en un bol un buen chorro de aceite, sal y una pizca de comino.

Sazona el sargo por dentro y rellena la tripa con el salteado de verduras y unas ramas de cilantro. Úntalo por fuera con el aliño y hornea a $180^{\circ} \mathrm{C}$, durante $30 \mathrm{mi}$ nutos.

Para la salsa tarator, mezcla en un bol el tahín con el zumo de limón y el cilantro picado. Vierte agua tibia poco a poco y mezcla bien hasta hacer una salsa fina. Prueba el punto de sal.

Sirve el sargo en un plato con las verduras, acompaña con la salsa tarator y espolvorea con perejil picado.

Además de su escasa validez descriptiva, especialmente en lenguas como la española, la caracterización del párrafo que venimos comentando es también problemática desde otro punto de vista, no menos importante, como es la concepción metodológica general sobre la que descansa. Al asociarse el funcionamiento del párrafo al papel que jugarían determinadas unidades como la oración, parece estarse planteando una jerarquización de niveles lingüísticos en la que en la que el párrafo se situaría en la misma escala que la

\footnotetext{
${ }^{1}$ http://www.hogarutil.com/cocina/recetas/pescados-mariscos/201204/sargo-libanesa-14824.html.
} 
oración, ocupando un lugar inmediatamente superior respecto de esta, tal y como podríamos representar en $(2)^{2}$ :

(2)
g) Texto<smiles>CC(C)(C)C</smiles>
e) Párrafo<smiles>[CH]1CC1</smiles>
d) Oración<smiles>[CH]1CC1</smiles>
c) Sintagma
b) Palabra<smiles>[CH]1CC1</smiles>
a) Morfema

Esta conceptuación del párrafo como elemento situable en la escala de las unidades lingüísticas en tanto que estadio de la misma naturaleza general que las unidades prototípicamente gramaticales puede encontrarse en estudios como los de Longacre (1996: 101), para quien un párrafo está constituido por dos o más "sentences" semánticamente relacionadas o, de manera casi incidental (Longacre 1996: 293), por una sola de tales unidades, de acuerdo a unos planteamientos según los cuales se entiende por "sentence" una unidad superior a la "cláusula" en la que se producen determinadas relaciones de naturaleza semántico-comunicativa. En términos parecidos se concreta la concepción del párrafo de Pike (1967), o Becker (1966), y una perspectiva semejante, en lo que se refiere a esta visión de las relaciones jerárquicas de constitución, puede encontrarse en planteamientos como los de García Berrio y Albaladejo (1983: 165), para quienes el párrafo estaría "constituido por unidades microestructurales, por oraciones...".

\footnotetext{
${ }^{2}$ En la escala de niveles representada, b) estaría en lugar de los niveles/unidades discursivos intermedios entre la unidad superior, el TEXTO, y el PÁRRAFO. Representamos con una flecha vertical las relaciones de constitución que se darían entre cada unidad y la jerárquicamente inferior, tomando en consideración en el plano de la gramática tan solo las unidades dotadas de significado.
} 
No obstante, aunque pueda ser cierto, estadísticamente hablando, que la forma prototípica del párrafo en la mayoría de textos escritos coincidiría con una variante en la que las unidades constitutivas serían oraciones, no lo es menos que es perfectamente posible encontrar párrafos materializados gramaticalmente a través de unidades de niveles inferiores a la oración. Este rasgo, que resulta especialmente característico de la denominada conversación coloquial, puede encontrarse también en los textos escritos, con mayor frecuencia, seguramente, según disminuya su complejidad y grado de institucionalización. Así podría suceder, por ejemplo, en textos escritos de complejidad mínima como los de carteles que buscan advertir sobre determinadas situaciones muy concretas de especial relevancia en determinadas circunstancias, como los de (3) - (5):

(3) ¡Perros sueltos!

(4) Peligro de incendio

(5) iSilencio!

Una representación explicativamente más adecuada de las relaciones que se producen entre las unidades que hemos incluido en (2) sería, por tanto, la de (6) donde, fundamentalmente, se desea representar que las unidades del dominio de lo textual configuran un espacio metalingüístico diferente del estrictamente gramatical, y donde, en lugar de postular que el párrafo es, prototípicamente, la unidad jerárquicamente superior a la oración, y, desde un punto de vista composicional, una combinación de oraciones, se asume que este puede materializarse a través de unidades gramaticales de distinta naturaleza: oraciones, sintagmas, palabras...

La jerarquización de planos y unidades esquematizada en (6) llevaría de manera natural a la conclusión de que las unidades que representamos como e) -es decir, los constituyentes del párrafo- en tanto que unidades del plano discusivo han de ser, como las restantes unidades del mismo plano, unidades de naturaleza semántica.

(6)

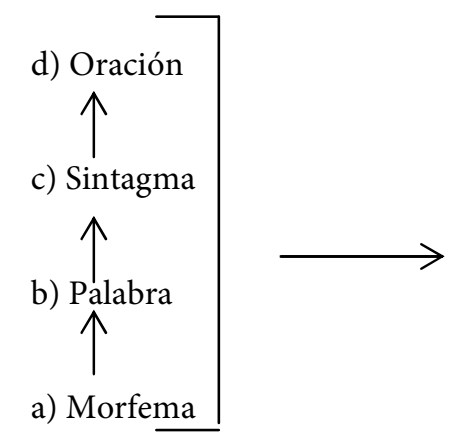

PLANO GRAMATICAL

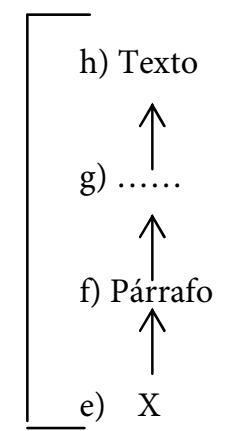

PLANO DISCUSIVO 
Van Dijk (1980) ha propuesto como unidades características de dicha función las que denomina macroproposiciones, unidades sintáctico-semánticas que vienen a ser el equivalente de la combinación de una determinada enunciación más un enunciado que transmite un determinado contenido conceptual modalizado desde una cierta perspectiva enunciadora, de forma tal que, en condiciones de no mínima complejidad, un párrafo vendría a ser una unidad constituida por varias macroproposiciones.

El modelo lingüístico-textual desarrollado por Van Dijk es, en nuestra opinión, un simulacro metodológico muy coherentemente desarrollado, en cuyo marco es posible encontrar también una respuesta adecuada a la cuestión que nos interesa: las características fundamentales que sirven para definir al párrafo como unidad lingüístico-textual. En dicho modelo, el texto es definido como una unidad de comunicación de naturaleza fundamentalmente semántico-sintáctica cuya operatividad se concreta en la existencia de un plano de análisis que denomina macroestructura textual. Una macroestructura textual estaría constituida por las unidades elementales que Van Dijk denomina macroproposiciones. Estas unidades sintáctico-semánticas, equivalentes, como señalábamos más arriba, a la combinación de una determinada enunciación con un enunciado, transmiten un determinado contenido conceptual modalizado desde una cierta perspectiva enunciadora.

Un texto, no obstante, no puede ser explicado como una secuencia formada exclusivamente por unidades del tipo de las macroproposiciones, sino que, en el esquema representado en (5), es necesario reservar un espacio entre los niveles señalados como e), el nivel textual, y g), el correspondiente a la macroproposición, para otros que se corresponden con unidades textuales intermedias. Uno de tales estadios, estratos o niveles textuales se corresponde claramente con el paragráfico, en tanto que, como ha propuesto Van Dijk (1980), espacio textual donde se desarrolla un determinado tópico discursivo, o base semántico-conceptual que representa como superordenado al contenido conceptual de una determinada sección del texto o, más precisamente, de la macroestructura textual, y que puede ser formalizado, a su vez, como una macroproposición ${ }^{3}$.

Es preciso no perder de vista, en todo caso, que esta última unidad, en tanto que unidad de la macroestructura, puede poseer un estatuto diferente según el nivel macroestructural que se represente a su través, de manera que, además de ser una unidad elemental en el análisis de la dimensión más terminal de la macroestructura, es también

\footnotetext{
${ }^{3}$ Van Dijk (1981) denomina episodio al contenido semántico del párrafo, tal y como queda formalizado en una secuencia de proposiciones. En paralelo a esta dimensión semántica, le correspondería a la unidad párrafo la condición de plano formal de manifestación del anterior.
} 
un elemento/unidad meta-metadiscursivo por referencia al párrafo, donde constituye el modo de representación de un tópico discusivo que, potencialmente, puede corresponder a un conjunto de macroproposiciones en el caso de párrafos complejos.

Podemos, en conclusión, definir el párrafo como la unidad discursiva/textual a través de la cual el emisor textual transmite, en los textos escritos, un determinado tópico discursivo. Se trataría, por tanto, desde el punto de vista semántico, de una unidad de evidente relevancia macroestructural, por corresponderse con un estadio relevante tanto en el proceso de producción textual, como en el de recepción.

Definido en tales términos, es clara la importancia o centralidad del párrafo entre las unidades o componentes esenciales del texto, en tanto que elemento que coincide con un estadio de densidad semántico-conceptual de la mayor relevancia en la decodificación del sentido global de aquel.

La importancia del párrafo como unidad textual desde un punto de vista cognitivo no es, ciertamente, menor. Como unidad de la macroestructura textual (o lo que es lo mismo - Van Dijk (1980) - de las informaciones del texto que el receptor almacena en su memoria a medio y largo plazo), el párrafo puede ser considerado, desde el punto de vista de la recepción o síntesis textual, como equivalente de una señal que marca la presencia de un momento o estadio cognitivo importante: el de un bloque de información relevante para el procesamiento macroestructural de aquel; un estadio de dicho procesamiento que puede encerrar procesos de distinto grado de complejidad. En el caso de párrafos constituidos por una única macroproposición, un procesamiento de complejidad mínima, pues la señalización como párrafo de dicha unidad supondría tan solo la necesidad de procesarla como tópico discursivo de la macroestructura, sin necesidad de ningún otro trámite añadido para poder almacenarla directamente en la memoria. En el caso de párrafos constituidos por secuencias de macroproposiciones en mayor número y complejidad, un procesamiento mediante las reglas que Van Dijk (1980: 213-218) propone como mecanismos para la construcción de la macroestructura textual, que permiten el procesamiento de sus contenidos y relaciones funcionales para simplificar dicho material inicial mediante su transformación en una nueva macroproposición que sirva como tópico discursivo de las secuencias transformadas.

La dimensión gráfica del párrafo, el sangrado de línea inicial y la preceptiva conclusión en un punto y aparte, más allá de ser una mera convención gráfica, funciona realmente como un significante semiótico en la medida en que señala la presencia de un determinado estadio de la organización macroestructural del texto. Dicho significante parece tener unas bases perceptivas universales que, concretadas en el caso de los mecanismos relacionados con la linealidad, descansan en la vinculación existente entre la percepción de las discontinuidades en las cadenas lineales y los procesos de activación 
de mecanismos visuales y cognitivos de percepción y decodificación semánticoconceptual de las comunicaciones. Así, Kuperman, Dambacher, Nuthmann y Kliegel (2010) han señalado cómo los párrafos se corresponden, desde el punto de vista de la percepción visual, con procesos de reconocimiento que se activan en el inicio de tales unidades y que demoran su recorrido o barrido en su final durante un tiempo significativo, por coincidir con el instante en que se procesa cognitivamente el material percibido visualmente hasta el momento, para lo que se requeriría un tiempo superior al necesitado previamente. En términos equivalentes, Hofmann (1989) ha puesto en relación la señal de final de párrafo con un mecanismo de invitación a la reflexión o valoración de la información percibida hasta ese instante. Igualmente, González Cobas (2008) ha señalado cómo, a medida que nos acercamos al final del párrafo, leemos más despacio.

Una caracterización exhaustiva de la naturaleza de la unidad textual párrafo hace preciso, atender, además de a su definición como unidad semántico-macroestructural, a la descripción de los aspectos esenciales de su comportamiento sintáctico y pragmático.

Desde un punto de vista sintáctico, los párrafos son unidades potencialmente complejas, de forma que, junto a unidades de este tipo constituidas por una única macroproposición, es posible encontrar otras integradas por un número más elevado de macroproposiciones. Esta situación pone claramente de manifiesto que, desde un punto de vista constitutivo ${ }^{4}$, los párrafos son unidades cuya estructura sintáctica bascula sobre relaciones sintácticas, o funciones, de tipo nuclearidad/marginalidad; es decir, en la posibilidad de construir una de tales unidades, como constructo, articulando a sus constituyentes macroproposicionales en función de núcleo o margen paragráfico. Desde un punto de vista dependencial, las macroproposiciones que constituyen el párrafo pueden, a su vez, establecer relaciones que, siguiendo algunos estudios como los realizados por

\footnotetext{
${ }^{4}$ Las diferencias entre las relaciones constitutivas (o relaciones sintácticas entre el constituto y sus constituyentes inmediatos) y de dependencia (o relaciones sintácticas de los constituyentes inmediatos de una unidad entre ellos) han sido abordadas en el ámbito de la sintaxis oracional en distintos trabajos. Véanse para unos estudios detallados Rojo (1979 y 1983). Alarcos (1977), Gutiérrez Ordóñez (1983), y Vera Luján (1994). Este punto de vista permite, en el plano de las relaciones de dependencia, establecer una tipología de relaciones sintácticas que no se limita a dos únicas clases (coordinación y subordinación), como suele ser habitual en muchos modelos gramaticales-oracionales, y también en otros de orientación discusiva. Es el caso de los planteamientos, por ejemplo, de Longacre (1996: 103), quien considera que las funciones sintácticas que pueden desempeñar dentro del mismo los constituyentes de un párrafo son las de elemento dominante o elemento ancilar, denominaciones básicamente equivalentes a las de elemento nuclear o elemento marginal. En sentido semejante, estas relaciones se corresponderían, dentro de la Teoría de las estructuras retóricas, con las que Mann y Thompson (1987a y 1987b) denominan núcleo y satélite, respectivamente.
} 
G. Rojo (1978 y 1983) sobre la estructura sintáctica interna de la unidad que denomina oración, o, más específicamente, propuestas como las realizadas a propósito de la estructura sintáctica interna de las intervenciones en el discurso oral (Portolés, 1986), cabe adscribir a tres grandes clases: de independencia funcional, o constelación, de dependencia o determinación, y de interdependencia o interordinación. Estas relaciones dependenciales se actualizan en forma de relaciones semántico-discursivas que forman parte del contenido transmitido a través de las macroproposiciones no simples de la macroestructura de un texto, como un contenido más de las mismas, según una variedad de tipos semánticos cuyo inventario no puede considerarse cerrado hasta la fecha pues existen distintas clasificaciones parcialmente no coincidentes y aun claramente parciales ${ }^{5}$.

Así pues, desde el punto de vista de su complejidad sintáctica interna, los párrafos pueden adscribirse a una de las cuatro clases representadas en (7), obtenidas, en último término, de la consideración de las relaciones de dependencia que pueden establecer sus constituyentes entre sí:

(7) i. Párrafo simple: constituido por una única macroproposición ii. Párrafo compuesto: constituido por más de una macroproposición

a. Párrafo compuesto por coordinación: constituido por varias macroproposiciones sujetas a relaciones de constelación.

b. Párrafo compuesto por subordinación: constituido por varias macroproposiciones sometidas a relaciones de dependencia unilateral.

c. Párrafo compuesto por interordinación: constituido por varias macroproposiciones sometidas a relaciones de interordinación.

La atención a la dimensión sintáctica del párrafo es también de utilidad para poder perfilar una imagen definida de sus límites y extensión mismos, atendiendo al número de elementos que pueden ser articulados en dicha unidad. Basándonos en Longacre (1996), para quien existen a este respecto dos tipos generales de estructuras paragráficas: las que pueden estar integradas por un número abierto de constituyentes, y las que, al contrario, presentan un perfil binario cerrado, aunque no coincidiendo con él en restringir estas dos posibilidades, grosso modo, a las relaciones de coordinación y su-

\footnotetext{
${ }^{5}$ Junto a las relaciones propuestas por Longacre (1996), pueden tomarse en consideración otras como las que Mann y Thompson (1987a, 1987b) formulan en el marco de la Teoría de la estructura retórica. Otra aproximación, basada esta vez en la identificación de marcadores discursivos, es decir, de elementos formales capaces de señalar la presencia de determinadas relaciones, es la de los trabajos de Martín Zorraquino y Portolés (1999) y Portolés (1998), entre otros.
} 
bordinación, sino poniéndolas en relación con una tipología de relaciones combinatorias como la indicada en (7), podríamos establecer que las unidades paragráficas podrían tener una estructura de las siguientes facturas constitutivas: de un tipo coordinativo, o constituido por un número potencialmente abierto de constituyentes en relación de constelación, como (8), que recoge las instrucciones de una receta de cocina ${ }^{6}$, y cuya estructura general se representa en (8i); de un tipo subordinativo, como $(9)^{7}$, cuya estructura sintáctica general representamos en (9i), donde señalamos las relaciones que afectan a esta estructura bipolar, según los planteamientos citados de Longacre; de un tipo interordinado, como $(10)^{8}$ y $(11)^{9}$ que se corresponden con las clases que Longacre denomina "párrafo de contraste" y "párrafo de razón" y que en su modelo se adscriben a tipos de estructuras diferentes, coordinadas y subordinadas, respectivamente, pero que en el que proponemos constituyen formas diferentes de un mismo tipo de relación de interordenación dado que la comprensión de mecanismos como los de "contraste" o "justificación” exige tomar en consideración, simultáneamente, a los dos elementos vinculados por unas relaciones de similar contenido que, de otra forma, desaparecerían conceptualmente.

(8) [Se elabora un caldo de pescado con pescado de no muy buena calidad, pero que tenga mucho sabor, como pueden ser morenas, congrios, generalmente pescado de mar muy espinoso. También se puede hacer con cabezas de pescado. El más fino a mi gusto es el hecho con cabeza de rape]1. [Se pone aceite en la paellera y se sofríen bien las gambas o camarón]2. [Se retiran]3. [Se sofríe la sepia, cuanto más pequeña se trocee mejor, y cuando se haya evaporado el agua que suelta, se introduce el tomate y poco después el pimentón]4. [A continuación se sofríe bien el arroz y se añade el caldo y el azafrán. El caldo ha de estar caliente en el momento de añadirlo. La proporción de caldo y arroz dependerá de si se hace en una paellera o en una olla convencional. En la paellera, al tener mayor superficie de evaporación, la proporción es de una taza de arroz por tres de caldo. En una olla será de una taza de arroz por dos de caldo]5. [Cuando esté a punto de terminar la cocción, se añaden las gambas]6.

\footnotetext{
${ }^{6} \mathrm{http} / / /$ www.recetasdecocina.es/recetas-443-Arroz-a-banda.html.

7 Tomamos el ejemplo de Longacre (1996: 112). Se trata de la clase de párrafos que denomina "de inferencia".

${ }^{8}$ Tomamos el ejemplo de Longracre (1996: 105). Se trata de la clase que denomina "párrafos de contraste".

${ }^{9}$ Tomamos el ejemplo de Longacre (1996: 109). Se trata de la clase que denomina “párrafos de razón”.
} 
(8i)

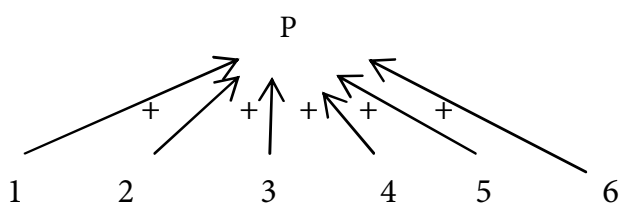

(9) [Me di cuenta enseguida de que algo no iba bien.]1 [Ella parecía atormentada, cansada y vieja]2. [Su voz sonaba carente de cualquier inflexión y absolutamente neutra.]3 [Había un gran moratón en el lado izquierdo de su cara.]4

(9i)

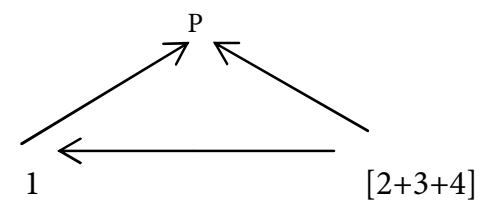

(10)[Los ciudadanos preocupados de esta ciudad, salid y votad en las próximas elecciones, y elegid a candidatos responsables como comisionados del condado] 1 . [Aquellos de vosotros a los que no les preocupa la calidad del gobierno local pueden quedarse en casa (¡No me importa!), y quejarse de cómo van las cosas.]2

(10i)

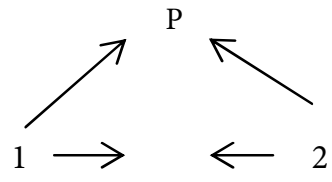

(11) [Se dejó caer por aquí para obtener otra comida gratis]1. [Confiaba en que siguiéramos siendo generosos.]2

(11i)

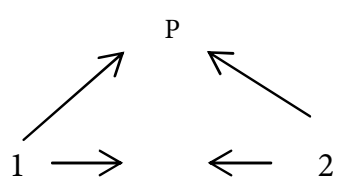

La propuesta de Longracre sobre la estructura sintáctica interna del párrafo contrasta, en mayor o menor grado, con otras realizadas desde modelos diferentes como la 
Teoría de las Estructuras Retóricas ${ }^{10}$ en la que las relaciones sintácticas postuladas entre los constituyentes de las unidades no simples se distribuyen en dos clases, las llamadas, "núcleo-satélite", configuradas como relaciones de subordinación, básicamente, y las denominadas "multinucleares", donde se encuadran tanto mecanismos como lo que hemos denominado de constelación como de interdependencia, manteniéndose, pues, básicamente, el postulado de la existencia de dos tipos de párrafos en lo que resulta del número de sus constituyentes inmediatos; párrafos abiertos, y párrafos binarios.

En otras perspectivas, como las que se centran en el estudio del discurso oral, el estudio de las unidades denominadas intervenciones o movimientos ha dado lugar a caracterizaciones de la estructura sintáctica de los mismos que parecen apartarse en alguna medida de las visiones binarias de la mayoría de estructuras paragráficas, postulando la existencia de intervenciones -dentro del tipo que llamaríamos "de subordinación"integradas por hasta tres o cuatro constituyentes menores, sometidos a relaciones de naturaleza semántica muy semejante a las reconocidas en la tagmémica o la "teoría de la estructura retórica".

A aproximar la imagen del párrafo estructural, en tanto que unidad transmisora de un determinado tópico discusivo en cuyo seno operan mecanismos sintácticosemánticos como los mencionados, a la del párrafo gráfico; es decir, a su manifestación superficial en forma gráfica como un espacio de escritura marcado por una sangría inicial de línea y un punto y aparte (o punto final), contribuyen también sin duda, de manera fundamental, los mecanismos de recursividad, que permiten "extender" linealmente las dimensiones del párrafo mediante la inclusión en su seno, en funciones propias de sus constituyentes prototípicos, las macroproposiciones, de unidades con las características necesarias para ser párrafos autónomos en otros contextos, pero que en estos usos no lo son, pues siguen remitiendo a un mismo tópico discursivo ${ }^{11}$.

En todo caso, las investigaciones realizadas sobre la estructura sintáctica interna del párrafo, o de unidades equivalentes en el discurso oral como la intervención ${ }^{12}$, permiten, sin duda, entender mejor, con referencia al párrafo, la naturaleza de los mecanismos de elaboración de las macroestructuras correspondientes, a partir de la información transmitida por las unidades macroproposicionales que lo integran. Parece razonable,

\footnotetext{
${ }^{10}$ Mann y Thompson (1987a y 1987b).

${ }^{11}$ Longacre (1996: 119-122), Roulet (1981).

${ }^{12}$ Veánse, para la caracterización de la unidad intervención, entre otros, los trabajos de Briz (2001), Portolés (1996), en representación de los estudios sobre la lengua oral realizados con los planteamientos metodológicos característicos del grupo Val.Es.Co., y en sentido semejante, aunque no coincidente en detalle, Roulet (1981) y Moeschler (1985).
} 
en efecto, suponer, que formarán parte del tópico discusivo que constituye el contenido macroestructural del párrafo (y que se representa en forma de una macroestructura simple o no simple) aquellas relaciones sintácticas, y los contenidos macroproposicionales que las contraen, que no entran dentro del tipo de las subordinativas, siendo las de interordinación las que, al contrario, gozarían de la capacidad de incorporarse a dicho contenido tópico-discusivo. De manera similar, parece razonable suponer también que los tópicos discursivos elaborados a partir de macroproposiciones en relación de subordinación habrían de construirse fundamentalmente como producto de operaciones de eliminación del contenido subordinado o dependiente, Igualmente, por último, parece también evidente que los párrafos compuestos por constituyentes macroproposicionales sujetos a relaciones de no-dependencia mutua, o constelación, serían espacios textuales especialmente adecuados para la operatividad de mecanismos del tipo de los que Van Dijk denomina construcción o generalización ${ }^{13}$; reglas de simplificación de la densidad semántica producto de la combinatoria macroproposicional en el párrafo mediante la elaboración de un hiperordenado capaz de representar como tópico discusivo a series de elementos coordinados, que podrían llegar a ser potencialmente muy extensas, de valor equivalente.

Una comprensión global del funcionamiento de la unidad párrafo no sería posible, finalmente, sin tomar en consideración la dimensión pragmática de dicha unidad. Se trata de una dimensión tan importante en la explicación del funcionamiento de las unidades discursivas o textuales, que algunos modelos, como los dedicados al estudio del discurso oral, suelen considerar como unidad básica de este tipo de discursos a la que denominan $a_{c t o}{ }^{14}$, cuyas propiedades coinciden en lo esencial con los actos de habla, objeto de estudio por excelencia de la Pragmática.

En términos del modelo de Van Dijk, que hemos asumido como el marco metodológico básico en el que desarrollar nuestra caracterización del párrafo, la perspectiva pragmática debe ser un tercer punto de vista esencial desde el que considerar a las macroproposiciones, junto con el sintáctico-semántico ya destacado.

El análisis del párrafo desde una perspectiva pragmática permite acceder a una faceta nueva del funcionamiento de esta unidad, en términos, esta vez, de su valor como unidad de acción comunicativa, como acto-tópico de habla. En paralelo a las consecuencias de los mecanismos sintáctico-semánticos de dominio párrafo>macroproposición respecto de la elaboración de los tópicos discursivos paragráficos, el funcionamiento

\footnotetext{
${ }^{13}$ Van Dijk (1980: 213 y ss.).

${ }^{14}$ Véase Briz (2001).
} 
pragmático del párrafo resultaría de la operatividad ya mencionada de las reglas de construcción macroestructurales establecidas por Van Dijk (1980) de acuerdo a su esquema de funcionamiento característico, solo que, ahora, dentro del dominio pragmático. Así, la condición del párrafo como tópico discursivo pragmático (como lo que hemos denominado más arriba acto-tópico de habla) se concretaría en unidades que podrían ser producto de la elaboración de los actos ilocutivos transmitidos por sus constituyentes según tres grandes tipos de mecanismos:

a) Los párrafos constituidos por macroproposiciones sometidas a relaciones mutuas de tipo subordinativo vendrían a funcionar pragmáticamente como actos-tópicos de habla de naturaleza similar a la del acto de habla macroproposicional que funciona como el constituyente nuclear del párrafo.

b) Los párrafos constituidos por macroproposiciones sometidas a relaciones mutuas de tipo constelativo vendrían a encontrar en el nivel del párrafo como acto-tópico discursivo equivalente un hiperodenado pragmático que representaría adecuadamente a la serie de actos ilocutivos macroestructurales.

c) Los párrafos constituidos por macroproposiciones sometidas a relaciones mutuas de interdependencia serían los candidatos perfectos para producir, en el citado nivel superior, actos-tópicos discursivos de carácter complejo, conservando en el nivel paragráfico todos los elementos ilocutivos que forman las partes esenciales de la relación sintáctico-pragmática.

La toma en consideración de la dimensión pragmática del párrafo no solo es de utilidad, como hemos señalado, para entender el modo en que dicha unidad funciona globalmente en el dominio de la acción comunicativa, sino también como una perspectiva complementaria imprescindible para poder entender en profundidad las relaciones combinatorias mismas que pueden tener lugar entre sus constituyentes (en el dominio pragmático, los actos macroposicionales), en la medida en que muchas de las posibilidades de sintagmación entre macroproposiciones son resultado de lo que Searle (1969, 1979) denominara condiciones de fortuna de los actos de habla, especialmente de las condiciones preparatorias, de sinceridad y esenciales, que pueden suministrar un material semántico-pragmático que sirva de marco para matizar en distintos sentidos a un acto nuclear, garantizando, por su ejemplo, su condición de acto discursivo cortés.

En consecuencia, el párrafo se configura, por tanto, como una unidad textual propia de la comunicación humana realizada a través de la lengua escrita que, en virtud de sus características de funcionamiento sintáctico, semántico y pragmático, se constituye como la unidad mínima de funcionamiento autónomo a través de la que se transmite 
un tópico discusivo de naturaleza semántico-conceptual que tiene un correlato pragmático en tanto que acto-tópico de habla.

Recibido: 23-XII-2011

Aceptado: 07-IV-2012

\section{Referencias bibliográficas}

Alarcos Llorach, E. (1977): "Metodología estructural y funcional en lingüística”, Revista de la Sociedad Española de Lingüística, 7/2, págs. 1-16.

Becker, A. L. (1966): "Contribution to the "Symposium on the Paragraph", College Composition and Communication, 17, 2, págs. 67-72.

Briz, A. (2001): El español coloquial en la conversación. Esbozo de pragmagramática. Barcelona, Ariel.

Brooks, R. y P. Warren (1949): Modern Rhetoric. New York, Harcourt.

Cassany, D. (1995): La cocina de la escritura, Barcelona: Anagrama.

Garachana, M. y E. Montolío (2000): “De la oración al párrafo. Del párrafo al texto”. En Montolío, E. (coord.): Manual práctico de escritura académica. Barcelona, Ariel, págs. 69-104.

García Berrio, A. y T. Albaladejo (1983): "Estructura composicional. Macroestructuras", ELUA, 1, págs. 127-180.

González Cobas, J. (2002): Párrafo y tópico de párrafo en la "Estoria España" de Alfonso $X$. Madrid, Universidad Autónoma de Madrid.

González Cobas, J. (2008): “Acerca del tópico del párrafo”, Verba Hispánica, 16, págs. 81-90.

Gutiérrez Ordóñez, S. (1983): "La determinación inmanente de las funciones en sintaxis", Contextos, 2, págs. 41-58.

Harris, Z. (1952): “Discourse Analysis", Language, 28, págs. 1-31.

Hofmann, T. R. (1989): "Paragraph sans Anaphora”, Journal of Pragmatics, 13, págs. 239-250.

Kuperman, V., M. Dambacher, A. Nuthmann y R. Kliegel (2010): "The effect of word position on eye-movements in sentence and paragraph reading", The Quarterly Journal of Experimental Psychology, 63 (9), págs.1838-1857.

Larsen, R. (1976): "Structure and Form in Non-Fiction Prose". En Tate, G. (ed.): Teaching Composition, 10. Forth Word, Christina University Press, págs. 45-71.

Longacre, R. E. (1979): “The paragraph as a grammatical unit”. En Givon,T. (ed.): Discourse and syntax, Syntax and Semantics 12. Nueva York, Academic Press, págs. 115-134. 
Longacre, R. E. (1996): The grammar of discourse. Nueva York, Plenum Press.

Mann, W. C. y S. A. Thompson (1987a): Rhetorical structure theory. A theory of text organization. Technical Report ISI/RW-87-190. Marina del Rey, CA: Information Sciences Institute.

Mann, W. C. y S. A. Thompson (1987b): "Rhetorical structure theory: a framework for analysis of texts", IPrA Papers in Pragmatics, 1, págs. 79-105.

Martín Zorraquino, Ma. A. y J. Portolés (1999): "Los marcadores del discurso". En Bosque, I. y V. Demonte (dirs.): Gramática descriptiva de la lengua española. Madrid, Espasa Calpe-Real Academia Española, págs. 4051-4213.

Moeschler, J. (1985): Argumentation et conversation. Éléments pour l'analyse linguistique $d u$ discours. Ginebra, Peter Lang.

Pike, K. L. (1967): Language in Relation to a Unified Theory of the Structure of Human Behavior. La Haya, Mouton.

Portolés, J. (1998): Marcadores del discurso. Barcelona, Ariel.

Portolés, J. (1996): "Sobre la organización interna de las intervenciones". En Briz, A., M. ${ }^{a}$ J. Martínez y Grupo Val.Es.Co. (eds.): Pragmática y gramática del español hablado. Valencia, Universidad de Valencia y Libros Pórtico, págs. 203-214.

RAE (1981): Esbozo de una nueva gramática de la lengua española. Madrid, EspasaCalpe.

Rojo, G. (1979): “La función sintáctica como forma de significante”, Verba, 6, págs. 107151.

Rojo, G. (1983): Aspectos básicos de sintaxis funcional. Málaga, Ágora.

Roulet, E. (1981): "Échanges, interventions et actes de langage dans la structure de la conversation”, Études de Linguistique Appliquée, 44.

Sánchez Escobar, A. (1996): "La retórica contrastiva del párrafo inglés y español y sus repercusiones en la enseñanza de inglés escrito”. En Martín Vázquez, M. (coord.): Gramática contrastiva inglés-español. Huelva, Universidad de Huelva.

Searle, J. R. (1969): Speech Acts. Cambridge, Cambridge University Press.

Searle, J. R. (1979): Expression and Meaning. Cambridge, Cambridge University Press.

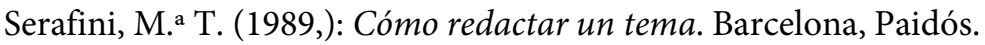

Van Dijk, T. A. (1980): Texto y contexto (semántica y pragmática del discurso). Madrid, Cátedra.

Van Dijk, T. A. (1981): "Episodes as units of discourse analysis". En Tannen, D. (ed.): Analyzing Discourse: Text and Talk. Georgetown, Georgetown University Press, págs. 177-195.

Vera Luján, A. (1994): Fundamentos de análisis sintáctico (de la palabra al texto). Murcia, Secretariado de publicaciones de la Universidad de Murcia. 